\section{Blue versus Red Light Can Promote Elongation Growth Independent of Photoperiod: A Study in Four Brassica Microgreens Species}

\author{
Yun Kong, Devdutt Kamath, and Youbin Zheng \\ School of Environmental Sciences, University of Guelph, 50 Stone Road East, \\ Guelph, ON N1G 2W1, Canada
}

Additional index words. hypocotyl length, light quality, lighting duration, petiole length, seedling, stem extension rate

\begin{abstract}
An elongated stem has beneficial effects on microgreen production. Previous studies indicate that under 24-hour light-emitting diode (LED) lighting, monochromatic blue light, compared with red light, can promote plant elongation for some species. The objective of this study was to investigate whether shortened photoperiod can change blue vs. red light effects on elongation growth. The growth and morphology traits of arugula (Brassica eruca, 'Rocket'), cabbage (Brassica oleracea, unknown variety name), mustard (Brassica juncea, 'Ruby Streaks'), and kale (Brassica napus, 'Red Russian') seedlings were compared during the stage from seeding to cotyledon unfolding under two light quality $\times$ two photoperiod treatments: 1) $R$, monochromatic red light $(665 \mathrm{~nm})$ and 2) $B$, monochromatic blue light $(440 \mathrm{~nm})$ using continuous (24-hour light/0-hour dark) or periodic (16-hour light/8-hour dark) LED lighting. A photosynthetic photon flux density of $\approx 100 \mu \mathrm{mol} \cdot \mathrm{m}^{-2} \cdot \mathrm{s}^{-1}$ and an air temperature of $\approx 22{ }^{\circ} \mathrm{C}$ was used for the preceding treatments. After 7 to 8 days of lighting treatment, regardless of photoperiod, $B$ promoted elongation growth compared with $R$, as demonstrated by a greater stem extension rate, hypocotyl length, or petiole length in the tested microgreen species, except for mustard. The promotion effects on elongation were greater under 24- vs. 16-hour lighting in many cases. Among the tested species, mustard showed the lowest sensitivity in elongation response to $B$ vs. $R$, which was independent of photoperiod. This suggests that the blue-light-promoted elongation is not specifically from 24-hour lighting, despite the varying promotion degree under different photoperiods or for different species. The elongation growth promoted by blue LED light under a photoperiod of either 24 hours or 16 hours can potentially benefit indoor production of microgreens.
\end{abstract}

Microgreens are consumed when cotyledons are fully expanded, retaining their typical color, with or without appearance of the first true leaves (Jones-Baumgardt et al., 2019; Kyriacou et al., 2016). Microgreens can be grown in varying scenarios, including outdoor, greenhouse, and indoor environments (Kyriacou et al., 2016). LED lighting has been increasingly used as a sole light source for indoor production of vegetables such as microgreens (Kozai et al., 2015).

Most microgreens are harvested at 7 to $21 \mathrm{~d}$ from seeding with a minimum height of $\approx 5 \mathrm{~cm}$ (Kyriacou et al., 2016). Also, commercial microgreen production has been increasingly switching from hand- to machine-

Received for publication 13 June 2019. Accepted for publication 14 Aug. 2019.

We thank Natural Sciences and Engineering Research Council of Canada and Greenbelt Microgreens Ltd. for their financial support awarded to Dr. Youbin Zheng. We also thank LumiGrow, Inc. (Emeryville, CA) for providing LED lighting technologies for this study and David Llewellyn for his excellent technical support during the trial. Y.Z. is the corresponding author. E-mail: yzheng@ uoguelph.ca. harvesting to reduce labor cost. Microgreens with hypocotyls $<5 \mathrm{~cm}$ are difficult for machine-harvesting, according to the communication with some Canadian growers. It is well known that both red and blue light can mediate stem elongation (Huché-Thélier et al., 2016). Also, monochromatic red and blue LED lights have been successfully used for microgreen cultivation with the advantage of increasing beneficial phytochemicals such as antioxidants (Kopsell and Sams, 2013; Wu et al., 2007). However, limited information is available on the effect of monochromatic red and blue LED lights on stem elongation of microgreens, especially under different photoperiods, because photoperiod can also affect this plant trait (Bergstrand, 2017).

Previous studies indicated that under LED lighting at a photosynthetic photon flux density (PPFD) of $100 \mu \mathrm{mol} \cdot \mathrm{m}^{-2} \cdot \mathrm{s}^{-1}$ or 50 $\mu \mathrm{mol} \cdot \mathrm{m}^{-2} \cdot \mathrm{s}^{-1}$, monochromatic blue vs. red light promoted elongation growth in all the tested bedding plant species, including petunia, calibrachoa, geranium, and marigold (Kong et al., 2018), and some microgreen species such as arugula, cabbage, and kale (Kong et al., 2019). In these studies, a photoperiod of $24 \mathrm{~h}$ was used for lighting treatments. Possibly the blue-light-promoted elongation growth is an artifact specifically from 24-h lighting because it is well known that most plants grow naturally under a periodic light/dark environment. However, similar promotion effects by blue vs. red light have also been achieved under a photoperiod of $<24 \mathrm{~h}$ (i.e., $12-18 \mathrm{~h}$ ) in other LED studies on seedlings of eggplant (Hirai et al., 2006), cherry tomato (Kim et al., 2014), cucumber (Hernández and Kubota, 2016), marigold (Heo et al., 2002), and sunflower (Schwend et al., 2015) at a PPFD of $\approx 100$ $\mu \mathrm{mol} \cdot \mathrm{m}^{-2} \cdot \mathrm{s}^{-1}$. Thus, under a certain range of light levels (e.g., $100 \mu \mathrm{mol} \cdot \mathrm{m}^{-2} \cdot \mathrm{s}^{-1}$ ), the promoted stem elongation growth by monochromatic blue light, relative to red light, might be a common phenomenon when photoperiod varied between 12 and $24 \mathrm{~h}$. However, this speculation needs confirmation because the preceding studies were performed with different species under different environments. For indoor production, 16-h lighting daily has become popular (Kozai, 2018). When photoperiod is shortened from $24 \mathrm{~h}$ to $16 \mathrm{~h}$, it is unknown whether blue vs. red LED lighting at a PPFD of $100 \mu \mathrm{mol} \cdot \mathrm{m}^{-2} \cdot \mathrm{s}^{-1}$ could also promote elongation growth for some microgreen species.

Shortened photoperiod is known to reduce elongation for some species (Bergstrand, 2017; Schüssler and Bergstrand, 2012). Also, a recent study on petunia indicated that the stem elongation was not promoted by blue vs. red light until the exposure duration increased up to $5 \mathrm{~d}$, and the blue light promotion was proportional to the lighting duration time (Fukuda et al., 2016). It is possible that shortening photoperiod within a certain range may reduce, rather than eliminate, promotion effects of blue vs. red light on plant elongation at least in some species. However, in that study, the petunia plants developed expanded true leaves, so both photosynthesis and photomorphogenesis were involved in blue vs. red light effects on plant elongation under different lighting duration. For microgreens without appearance of true leaves, photomorphogenesis is the main contributor to plant elongation. Therefore, it needs confirmation in the microgreens that shortened photoperiod from $24 \mathrm{~h}$ to $16 \mathrm{~h}$ can reduce blue light promotion effect on elongation to some degree.

Arugula, cabbage, kale, and mustard are popular species used for microgreen production. In a previous study on these microgreens with unfolded true leaves under 24-h lighting, different species varied in their elongationpromotion response to blue vs. red light at a PPFD of $100 \mu \mathrm{mol} \cdot \mathrm{m}^{-2} \cdot \mathrm{s}^{-1}$, showing a lower sensitivity in mustard than other species (Kong et al., 2019). However, it needs confirmation that microgreens without appearance of true leaves (i.e., from seeding to cotyledon unfolding) also differ in the blue light response among species. In addition to promoted elongation, some other typical shade-avoidance responses such as reduced side branch number and cotyledon size and increased biomass allocation to main stem also occurred under blue vs. red light, which 
varied with different species (Kong et al., 2018, 2019). It was concluded that blue-lightpromoted elongation is a shade-avoidance response with varying sensitivity among species (Kong et al., 2018, 2019). Unfortunately, the conclusion was drawn from the studies on some bedding plants and microgreens under 24-h lighting, although the shade-avoidance responses to blue light have been also reported for Arabidopsis under a photoperiod of $<24 \mathrm{~h}$ (de Wit et al., 2016; Keller et al., 2011; Pedmale et al., 2016). For microgreens, it is still unclear whether the species difference in blue light's effect on elongation as a shade-avoidance response could also be found under noncontinuous (e.g., 16-h) lighting.

On the basis of the preceding information, the following three hypotheses were proposed for arugula, cabbage, kale, and mustard seedling growth from seeding to cotyledon unfolding. Under LED lighting at a PPFD of $100 \mu \mathrm{mol} \cdot \mathrm{m}^{-2} \cdot \mathrm{s}^{-1}$ with a photoperiod of $24 \mathrm{~h}$ or $16 \mathrm{~h}, 1)$ shortened photoperiod $(16 \mathrm{~h})$ cannot eliminate the blue light promotion effect on plant elongation relative to red light, 2 ) the elongation promoted by blue light is greater under 24-h than 16-h lighting at least for some species, and 3) species differ in elongation response to blue light and the interspecies difference is unaffected by photoperiod. The objective of this study was to explore the mode of blue light action on plant elongation in four microgreen species by testing the foregoing hypotheses.

\section{Materials and Methods}

Plant materials and growing conditions. The experiment was conducted on four microgreen species with three replicates over time (Table 1) at the University of Guelph, Guelph, ON, Canada during the summer of 2018. Seeds were sown (one seed per cell) in 128 -cell $(8 \times 16$ cell $)$ trays containing Sunshine Mix \#5 substrate (Sun Gro Horticulture, MA). Each treatment had three trays in total. Each tray contained four species, and each species occupied two rows of cells in one tray. The sowed trays were placed inside a walk-in growth chamber to start the light treatment. The irrigation strategy and nutrient solution used for these plants were the same as those in the literature (Kong et al.,
2019). The temperature and relative humidity were set at $\approx 22{ }^{\circ} \mathrm{C}$ and $70 \%$, respectively.

Experimental design and treatments. The experiment was conducted as a $2 \times 2 \times 4$ factorial (photoperiod $\times$ light quality $\times$ plant species) in a split-split-plot design with three replicates over time (Table 1). The photoperiod, light quality, and plant species treatments were allocated to the main plots, subplots, and sub-subplots, respectively. For photoperiod treatments, continuous (24-h light/0-h dark) or periodic (16-h light/8-h dark) lighting were used, and for 16-h photoperiod, the lights were turned on between 9:00 AM and 1:00 AM. Light quality treatments included 1) R, monochromatic red light with a peak wavelength at $665 \mathrm{~nm}$; and 2) B, monochromatic blue light with a peak wavelength at $440 \mathrm{~nm}$. LED lighting system (Pro Series 325 ) was provided by LumiGrow, Inc. (Emeryville, CA).

For each replicate, two photoperiod treatments were randomly allocated to the two ends in the growth chamber, which were far away from each other to avoid neighboring effects. Also, within each photoperiod treatment plot, the two light quality treatments were randomly allocated to the two compartments. The locations of the four treatments of photoperiod $\times$ light quality were switched by changing the timer setting and light spectral output of the LEDs in each compartment for each of the three replicates (Table 1). For each replicate, a PPFD of around 100 $\mu \mathrm{mol} \cdot \mathrm{m}^{-2} \cdot \mathrm{s}^{-1}$ at the plant canopy level were achieved in each compartment by adjusting the light intensity output of the LEDs. Compartments were separated by curtains to prevent neighboring effects. Light spectra and intensities were set up and verified using a USB2000 + ultraviolet/VIS spectrometer (Ocean Optics, Inc., Dunedin, FL). The light levels and other environmental data of different light treatments are presented in Table 2 .

Growth and morphology measurements. When more than $50 \%$ of seeds germinated under all the treatments, the germination percentages were investigated. At the beginning of cotyledon unfolding, for each species, 16 plants in the middle cells were sampled from each treatment for each replicate to measure initial main stem (MS) length. At the end of the light treatments, the final MS length was measured on the same plants as those for initial measurement. On the basis of the MS measurements, stem extension rate (SER; $\mathrm{cm} \cdot \mathrm{d}^{-1}$ ) was calculated using Eq. [1],

$$
\mathrm{SER}=\frac{\mathrm{LS}_{\mathrm{f}}-\mathrm{LS}_{\mathrm{i}}}{3}
$$

where $\mathrm{LS}_{\mathrm{f}}$ and $\mathrm{LS}_{\mathrm{i}}$ are the final and initial MS lengths, respectively. The denominator, 3 , represents the number of days between the initial and final measurements for each plant species.

At $7 \mathrm{~d}$ (mustard and kale) and $8 \mathrm{~d}$ (arugula and cabbage) after the start of light treatments in each of the three replicates of the experiment, six plants from each species were randomly selected for observation of stem and cotyledon morphology under each light treatment combination (two light quality treatments $\times$ two photoperiod treatments). For the morphology observations, the sampled plants were cut at the root-shoot junction, and the cotyledons, with petioles, were cut from the stems. Then the stems were straightened, and the cotyledons were fully unfolded using sticky, clear, plastic tape and laid on an white sheet of A4 paper with the upper cotyledon surface outward. The papers with stems and cotyledons and the standard scale were then scanned using a CanoScan LiDE 25 scanner (Canon Canada Inc., Brampton, ON, Canada).

After scanning, another 10 plants from each species for each replicate were randomly selected for the measurements of biomass accumulation and partitioning. The sampled plants were cut at the root-shoot junction. After weighing the total aerial fresh weight $(\mathrm{FW})$, the aerial parts were separated into cotyledons with petioles, and stems. The separated aerial plant parts were put into two separate paper bags and dried in an oven at $65^{\circ} \mathrm{C}$ to determine dry weight (DW) of each component. The biomass partitioning trait, stem/aerial DW, was then calculated using Eq. [2].

$$
\begin{aligned}
& \text { Stem/aerial DW }(\%) \\
& =\frac{\mathrm{DW} \text { of stem }(\mathrm{g})}{\mathrm{DW} \text { of aerial part }(\mathrm{g})} \times 100
\end{aligned}
$$

After harvesting was completed for all the

\begin{tabular}{|c|c|c|c|c|c|}
\hline Common name & Scientific name & Plant color & Seed source & Seeding date & Harvesting date \\
\hline Cabbage & Brassica oleracea, Unknown name & Purple stem and leaf margin & $\begin{array}{l}\text { Mumm's Sprouting Seeds, } \\
\text { Parkside, SK, Canada }\end{array}$ & $\begin{array}{l}\text { Rep. 1: } 12 \text { July } \\
\text { Rep. 2: } 2 \text { Aug. } \\
\text { Rep. 3: } 16 \text { Aug. }\end{array}$ & $\begin{array}{l}\text { Rep. 1: } 20 \text { July } \\
\text { Rep. 2: } 10 \text { Aug. } \\
\text { Rep. 3: } 24 \text { Aug. }\end{array}$ \\
\hline Kale & Brassica napus, 'Red Russian’ & Purple stem with green leaf & $\begin{array}{l}\text { High Mowing Organic } \\
\text { Seeds, Wolcott, VT }\end{array}$ & $\begin{array}{l}\text { Rep. 1: } 12 \text { July } \\
\text { Rep. 2: } 2 \text { Aug. } \\
\text { Rep. 3: } 16 \text { Aug. }\end{array}$ & $\begin{array}{l}\text { Rep. 1: } 19 \text { July } \\
\text { Rep. 2: } 9 \text { Aug. } \\
\text { Rep. 3: } 23 \text { Aug. }\end{array}$ \\
\hline
\end{tabular}
seedlings, the scanned images were processed

Table 1. Information on the four microgreen plant species tested and the key time point for the experiment.

Rep. $=$ replicate 
Table 2. Environmental data for the different light quality and photoperiod treatments.

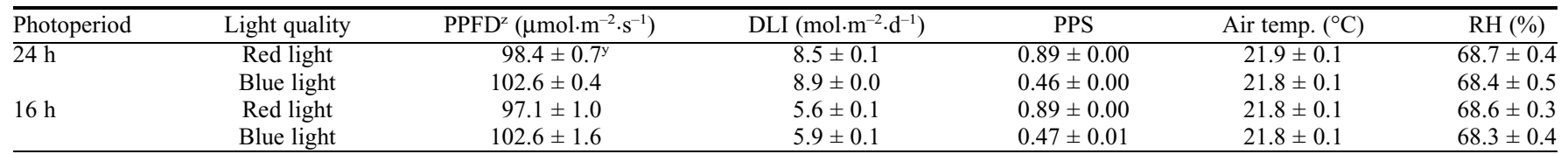

${ }^{\mathrm{z} P P F D}=$ photosynthetic photon flux density. The wavelength range 400 to $700 \mathrm{~nm}$ was used for calculating the PPFD. DLI $=$ daily light integral; PPS $=$ phytochrome photostationary state, which is the estimated phytochrome photoequilibrium according to the method by Sager et al. $(1988)$. $\mathrm{RH}=$ relative humidity. ${ }^{\mathrm{y}}$ Data are means \pm SE $(\mathrm{n}=3)$.

using ImageJ 1.42 software (National Institute of Health). Hypocotyl length, diameter, and color; cotyledon maximum blade length, maximum blade width, area, and color; and petiole length were determined from the scanned images. For hypocotyl and cotyledon color measurements, the detailed process could be found in the literature (Kong et al., 2019). Plant size and color measurements were calibrated by scanning a ruler and Munsell color chips (GretagMacbeth LLC, New Windsor, NY), respectively.

Statistical analysis. Data were subjected to analysis of variance using a Data Processing System Software (DPS, version 7.05; Refine Information Tech. Co., Hangzhou, China) and were presented as means \pm SE (standard error). Separation of means was performed using Duncan's new multiple range test at the $P \leq 0.05$ level. The $\mathrm{CV}$ under light quality treatments for each affected growth and morphological trait was calculated to compare variation magnitude of response to $\mathrm{B}$ vs. $\mathrm{R}$ light between the two photoperiod treatments and among the four plant species.

\section{Results}

There was no difference in germination under B and R light (data not shown). During the experimental period, plants under B vs. R light showed a greater SER regardless of photoperiod for cabbage, kale, and arugula (Fig. 1A). At harvest, both FW and DW of aerial parts were similar for the plants from $B$ and $\mathrm{R}$ light (data not shown). However, regardless of photoperiod, B vs. R light increased the ratio of stem/aerial DW for cabbage, kale, and arugula (Fig. 1B). The plants harvested from $B$ vs. $R$ appeared to be taller regardless of photoperiod for cabbage, kale, and arugula (Fig. 1C-F). There was an interaction effect between photoperiod and light quality on SER. Also, species interacted with light quality affecting SER and stem/ aerial DW ratio. However, there were no interaction effects on the two traits for photoperiod, species, and light quality.

For stem size, plants showed longer hypocotyl under $B$ than $R$ regardless of photoperiod, for cabbage, kale and arugula (Fig. 2A). However, there was no difference in hypocotyl diameter between plants under $\mathrm{B}$ and $\mathrm{R}$ for all the tested species (data not shown). For cotyledon size, regardless of photoperiod, B vs. R light increased petiole length for cabbage and arugula, reduced cotyledon area and maximum blade width for cabbage and kale, and maximum blade length for kale (Fig. 2B-E). There
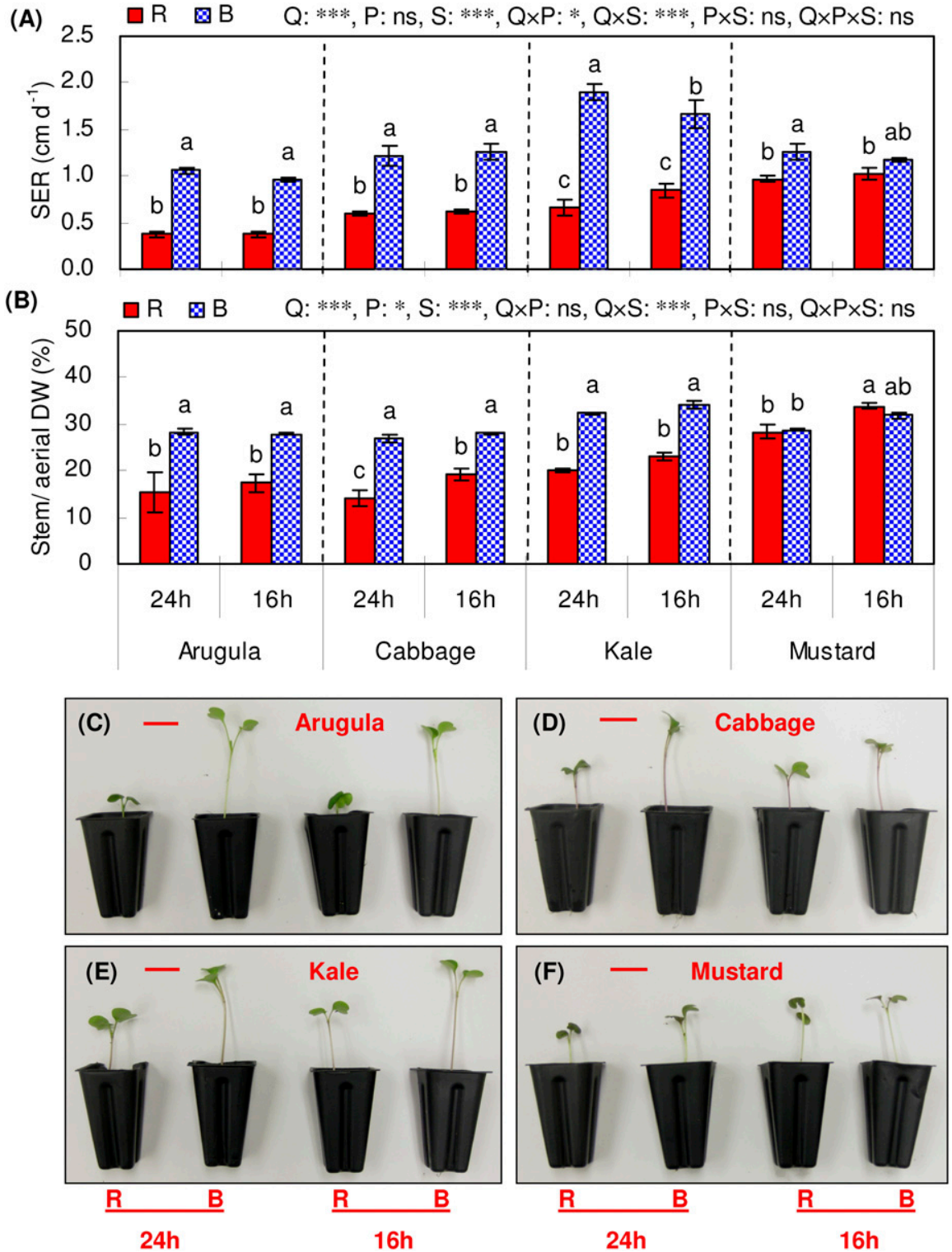

Fig. 1. Plant growth under different light treatments in four microgreen species. Data are means $\pm \operatorname{SE}(n=3)$. Pictures $(\mathbf{C}-\mathbf{F})$ were taken at 7 to $8 \mathrm{~d}$ from the start of light treatments. The reference bar length in these pictures is $1.6 \mathrm{~cm} . \mathrm{B}=$ monochromatic blue light; $\mathrm{R}=$ monochromatic red light; $\mathrm{SER}=$ stem extension rate. At the bottom of each panel, $24 \mathrm{~h}$ and $16 \mathrm{~h}$ indicate that the photoperiod is 24 and $16 \mathrm{~h}$, respectively. For a certain plant trait, symbols for light quality $(\mathrm{Q})$, photoperiod $(\mathrm{P})$, plant species $(\mathrm{S})$, or the interaction of light quality and photoperiod $(\mathrm{Q} \times \mathrm{P})$, light quality and plant species $(\mathrm{Q} \times \mathrm{S})$, photoperiod and plant species $(\mathrm{P} \times \mathrm{S})$, or light quality, photoperiod, and plant species $(\mathrm{Q} \times \mathrm{P} \times \mathrm{S})$ located closely above the frames followed by ns, *,**, or *** denote that treatment effects are not significant or significant at $P \leq$ $0.05,0.01$, or 0.001 , respectively. Within the same species, data bearing the same letter are not significantly different at $P \leq 0.05$, according to Duncan's new multiple range test.

were interaction effects between light quality and photoperiod on these traits except for maximum blade width. Also, species interacted with light quality, af- fecting all the plant size traits. However, there were no interaction effects on the plant size traits for photoperiod, species, and light quality. 
(A)

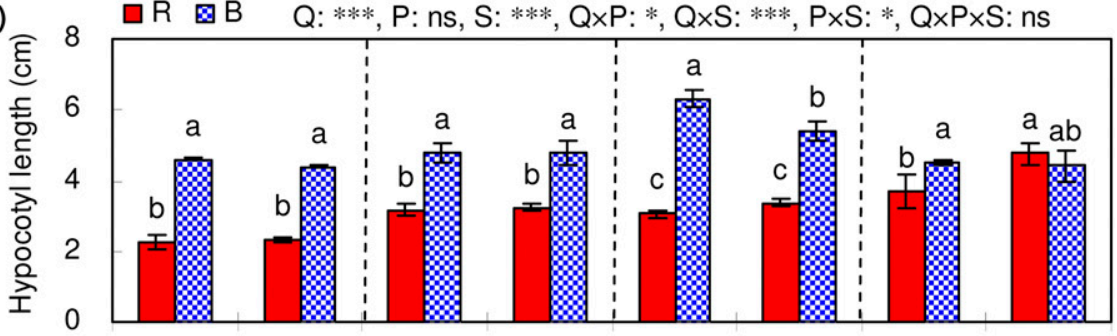

(B)

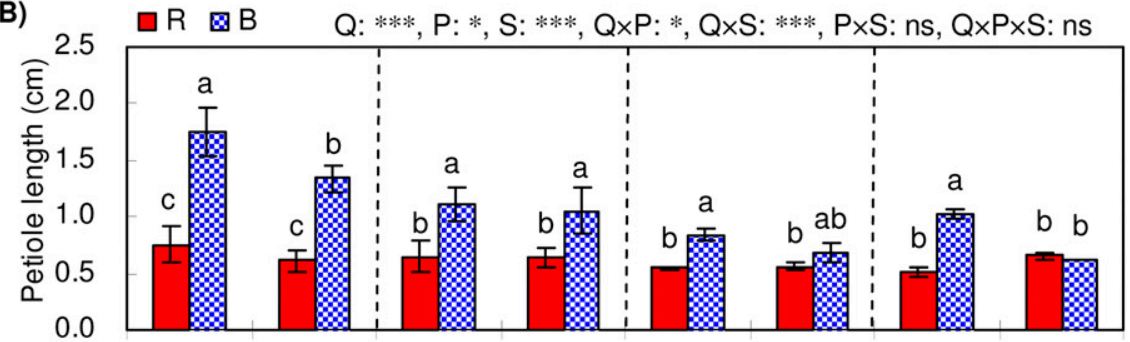

(C)

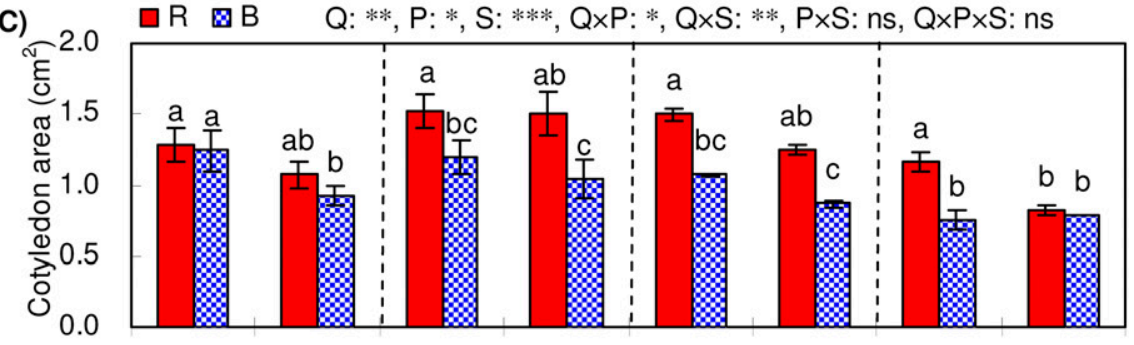

(D)

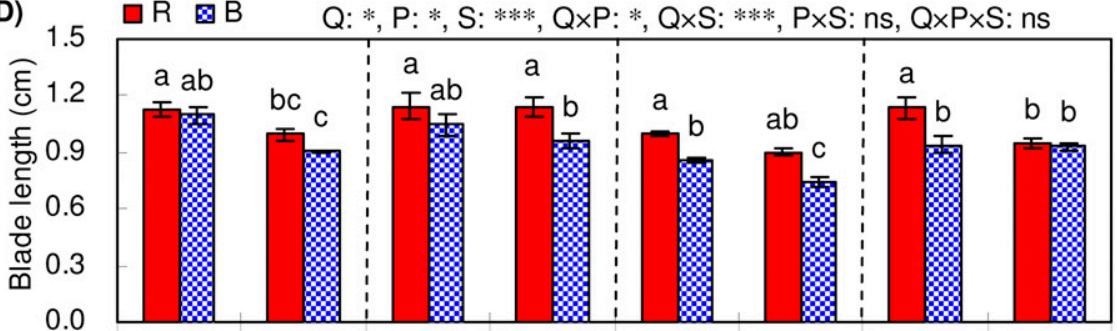

(E)

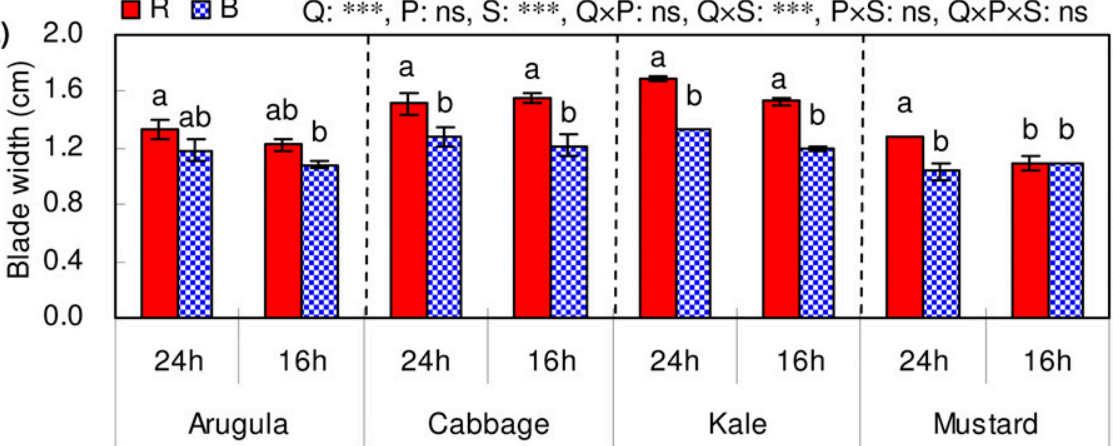

Fig. 2. Plant size traits under different light treatments in four microgreen species. Data are means $\pm S E(n=$ 3). $\mathrm{B}=$ monochromatic blue light; $\mathrm{R}=$ monochromatic red light. At the bottom of each panel, $24 \mathrm{~h}$ and $16 \mathrm{~h}$ indicate that the photoperiod is 24 and $16 \mathrm{~h}$, respectively. For a certain plant trait, symbols for light quality $(\mathrm{Q})$, photoperiod $(\mathrm{P})$, plant species $(\mathrm{S})$, or the interaction of light quality and photoperiod $(\mathrm{Q} \times$ $\mathrm{P})$, light quality and plant species $(\mathrm{Q} \times \mathrm{S})$, photoperiod and plant species $(\mathrm{P} \times \mathrm{S})$, or light quality, photoperiod, and plant species $(\mathrm{Q} \times \mathrm{P} \times \mathrm{S})$ located closely above the frames followed by ns, *,**, or $* * *$ denote that treatment effects are not significant or significant at $P \leq 0.05,0.01$, or 0.001 , respectively. Within the same species, data bearing the same letter are not significantly different at $P \leq 0.05$, according to Duncan's new multiple range test.

Generally there was no difference in cotyledon color between plants under B and $\mathrm{R}$ light (data not shown). For stem color, B vs. R did not change hue angle which was around $77^{\circ}$ (yellow-green), 354 ${ }^{\circ}$ (purple), $21^{\circ}$ (red), and $86^{\circ}$ (yellow-green) for arugula, tively. For these two traits, there were no interaction effects for photoperiod and light quality or for photoperiod, light quality, and species, but species showed interaction with light quality.

\section{Discussion}

Blue vs. red light can also promote plant elongation under noncontinuous lighting. In a previous study on microgreens, under $24-\mathrm{h}$ lighting at a PPFD of 50 or $100 \mu \mathrm{mol} \cdot \mathrm{m}^{-2} \cdot \mathrm{s}^{-1}$, $\mathrm{B}$ vs. $\mathrm{R}$ light promoted elongation growth for cabbage, kale, and arugula (Kong et al., 2019). In the present study, although the LED light, environmental conditions, and growth period were different from those in the previous study, B vs. R light under either 24- or 16-h lighting at a PPFD of 100 $\mu \mathrm{mol} \cdot \mathrm{m}^{-2} \cdot \mathrm{s}^{-1}$ promoted elongation growth by increasing stem extension rate, hypocotyl length, or petiole length for all the tested microgreen species except mustard. It confirmed the first hypothesis that shortened photoperiod ( $16 \mathrm{~h}$ ) cannot eliminate the blue light promotion effect on plant elongation relative to red light. In the present study, under either 16-h or 24-h lighting, blue-lightpromoted microgreen elongation met the demand of machine-harvesting (i.e., around $5 \mathrm{~cm}$ hypocotyl length). Also, under 16-h lighting, B vs. R light promoted elongation without compromising yield compared with 24-h lighting. Crop yield is important for microgreen growers because it directly affects economic return (Jones-Baumgardt et al., 2019). It implies that if blue light is used for microgreen production, shortening photoperiod from $24 \mathrm{~h}$ to $16 \mathrm{~h}$ may potentially reduce lighting cost and increase production efficiency.

The promoted elongation by B vs. R light was considered as one of the shade-avoidance responses mediated by blue light associated with weak phytochrome activity under certain light levels in previous studies (Kong et al., 2018, 2019). This conclusion was also supported by the results in the present study. B vs. $\mathrm{R}$ light has a much lower phytochrome photostationary state (PPS) value, $\approx 0.46$ vs. 0.89 (Table 2), and there is a general consensus that a PPS $>0.6$ can induce active-phytochrome response (Stutte, 2009). Monochromatic blue light seems to act like far-red light with regard to phytochrome. In addition to promoting elongation growth, B vs. R light also increased biomass partition to stem, reduced cotyledon size, or hypocotyl coloring showing typical shade-avoidance responses, which varied with different species. The reduced cotyledon size, or hypocotyl coloring under B vs. R light may negatively affect the appearance quality of microgreens to some degree because microgreens with large leaf size and deep stem color are normally more attractive to most consumers. In fact, the reduction of stem color in the present study was difficult to perceive by human vision possibly due to similar hue angle. Nevertheless, to reach a balance on the consideration of hypocotyl length and appearance quality (e.g., leaf size and stem 
(A)

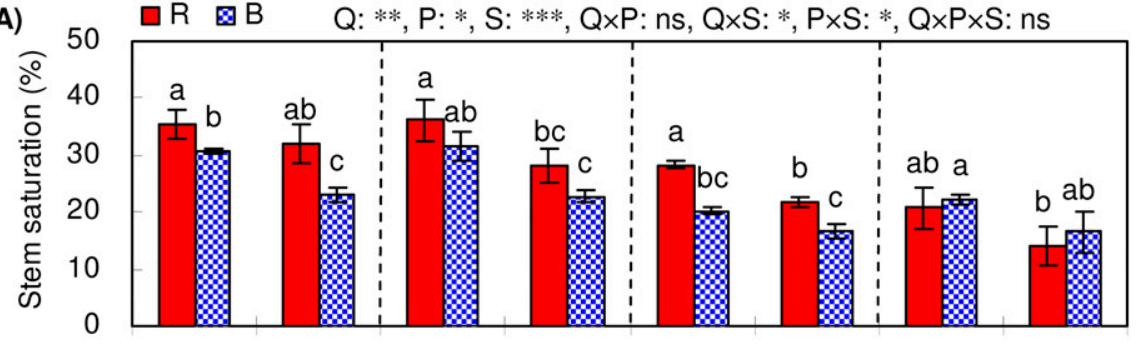

(B) $\quad \square \mathrm{R} \cap \mathrm{B} \quad \mathrm{Q}: * *, \mathrm{P}: * *, \mathrm{~S}: * * *, \mathrm{Q} \times \mathrm{P}: \mathrm{ns}, \mathrm{Q} \times \mathrm{S}: * * *, \mathrm{P} \times \mathrm{S}: \mathrm{ns}, \mathrm{Q} \times \mathrm{P} \times \mathrm{S}: \mathrm{ns}$

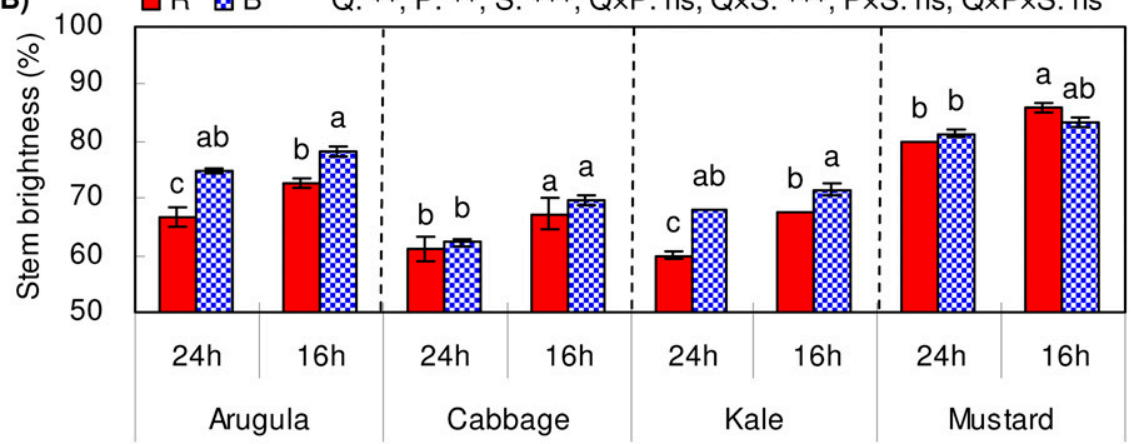

Fig. 3. Plant color under different light treatments in four microgreen species. Data are means $\pm S E(n=3)$ $\mathrm{B}=$ monochromatic blue light; $\mathrm{R}=$ monochromatic red light. At the bottom of each panel, the numbers, $24 \mathrm{~h}$ and $16 \mathrm{~h}$, indicate that the photoperiod is 24 and $16 \mathrm{~h}$, respectively. For a certain plant trait, symbols for light quality $(\mathrm{Q})$, photoperiod $(\mathrm{P})$, plant species $(\mathrm{S})$, or the interaction of light quality and photoperiod $(\mathrm{Q} \times \mathrm{P})$, light quality and plant species $(\mathrm{Q} \times \mathrm{S})$, photoperiod and plant species $(\mathrm{P} \times \mathrm{S})$, or light quality, photoperiod, and plant species $(\mathrm{Q} \times \mathrm{P} \times \mathrm{S})$ located closely above the frames followed by $\mathrm{ns}, *, * *$, or $* * *$ denote that treatment effects are not significant or significant at $P \leq 0.05,0.01$, or 0.001 , respectively. Within the same species, data bearing the same letter are not significantly different at $P \leq 0.05$, according to Duncan's new multiple range test.

color) of microgreens, after $\approx 7$-d blue light treatment, exposing these plants to red light for some days may be an option because these microgreen species can be harvested without or with unfolded first true leaves (i.e., 7-8 d or 11-14 d after seeding) (Jones-Baumgardt et al., 2019). This needs further study to confirm the feasibility.

It is worthwhile to note that in the previous study on the same microgreen species, $\mathrm{B}$ vs. R light changed cotyledon color (Kong et al., 2019). However, this change did not occur in the present study. The difference might be due to earlier plant harvest $(7-8 \mathrm{~d}$ vs. 11-14 d after seeding) in the present vs. previous study. The lighting treatment period for the present study was from seeding to cotyledon unfolding, so the unfolded cotyledons during de-etiolation experienced a very short period of lighting to elicit color changes. During the de-etiolation stage, cotyledon color changing from yellow to a genotype-inherent color such as green or red involves initiated chloroplast development or increased anthocyanin biosynthesis (Kong and Zheng, 2019). The difference in pigment formation under B vs. R light might not be obvious until the lighting treatments reached a certain time length. For example, seedlings of nonheading chinese cabbage increased chlorophyll content after 28 to $30 \mathrm{~d}$ of $\mathrm{B}$ vs. R LED light treatment (Fan et al., 2013; Li et al., 2012).

Blue light promotion effects on elongation are more obvious under 24- than non-24-h lighting. There were interaction effects be- tween photoperiod and light quality on the elongation growth traits in the present study. For the tested species, B vs. R light effects on elongation were greater under continuous than noncontinuous lighting in many cases (Fig. 4). For example, B vs. R light increased stem extension rate and hypocotyl length for mustard, and petiole length for mustard and kale under 24-h lighting rather than 16-h lighting. Under 24- vs. 16-h lighting, the B light promotion effects were greater for stem extension rate and hypocotyl length in kale and for petiole length in arugula. This confirmed our second hypothesis that the elongation promoted by blue light is more obvious under 24- than 16-h lighting at least for some species. It appears that continuous lighting might provide a better platform to present and even amplify B vs. R light effects on plant elongation at least for some species (Kong et al., 2018). In practical production, for the same lighting (e.g., blue LED light), if at similar light intensity levels, longer photoperiod (e.g., $24 \mathrm{~h}$ vs. $16 \mathrm{~h}$ ) means higher lighting cost, but using a lower light intensity for continuous (24-h) lighting is a way to balance it (Sysoeva et al., 2010). Our recent study on arugula and mustard indicates that when using 24-h LED lighting (blue or red), microgreens showed similar elongation growth under PPFD levels of 70-120 $\mu \mathrm{mol} \cdot \mathrm{m}^{-2} \cdot \mathrm{s}^{-1}$ (unpublished data). In this case, it is possible using 24-h lighting at a lower PPFD level to achieve a greater blue light promotion on microgreen elongation, without increasing lighting cost too much.
The difference in $\mathrm{B}$ vs. $\mathrm{R}$ light effects on elongation growth under different photoperiod could be partly explained by the fact that light quality also affected photoperiod effects on elongation growth. When photoperiod decreased from $24 \mathrm{~h}$ to $16 \mathrm{~h}$, plant elongation did not change under $\mathrm{R}$ light but was inhibited under B light for the aforementioned traits and species in most cases. For example, shorter photoperiod of B light reduced stem extension rate and hypocotyl length for kale and petiole length for arugula and mustard. Previous studies indicate that shortened photoperiod is known to reduce elongation possibly either due to the restriction of assimilates, or to the fact that gibberellin production is light-dependent (Bergstrand, 2017; Warrington and Norton, 1991; Yamaguchi, 2008). In the present study, there is a less possibility of assimilation restriction because during the short growth period (from seeding to cotyledon unfolding), microgreens mainly experienced a transition from heterotrophic to autotrophic growth, and photosynthesis contributed little to elongation growth (JonesBaumgardt et al., 2019). Also, in a previous study on petunia, bioactive gibberellins have shown higher levels under B vs. R light, which is related to blue-light-promoted elongation growth (Fukuda et al., 2016). So, at least for some species, gibberellin production might be reduced by shorter photoperiod of $B$ light rather than $\mathrm{R}$ light.

In addition to elongation growth, the interaction effects between photoperiod and light quality were also found on cotyledon size traits, such as area and maximum blade length. For mustard, B vs. R light reduced these two traits under 24-h lighting rather than 16-h lighting, suggesting that B light effects on cotyledon size were greater under continuous lighting than noncontinuous light for this species. When considering all the light-quality-affected plant traits together, in most cases, B vs. R light effects were greater under 24-h than 16-h lighting for the tested species except cabbage (Fig. 4). For cabbage, 24-h lighting showed the smallest difference from 16-h lighting in terms of $\mathrm{B}$ vs. $\mathrm{R}$ light promoted elongation growth, and this species even showed contrasting results from other species on cotyledon size (e.g., maximum blade length) (Fig. 2). Considering this point, when blue LED light is used for increasing plant elongation of cabbage microgreens, 16-h rather than 24-h lighting may be adopted in production. Although the involved mechanism for the species difference is not clear and needs further study, it suggests that species differences in blue light effects cannot be ruled out.

Species differences in blue light effects on elongation are independent of photoperiod. In the previous study on microgreens with unfolded true leaves, B vs. R light effects on the plant growth and morphology varied with species (Kong et al., 2019). Similar results were found in the present study despite shorter growth period (from seeding to cotyledon unfolding). This was supported by interaction 

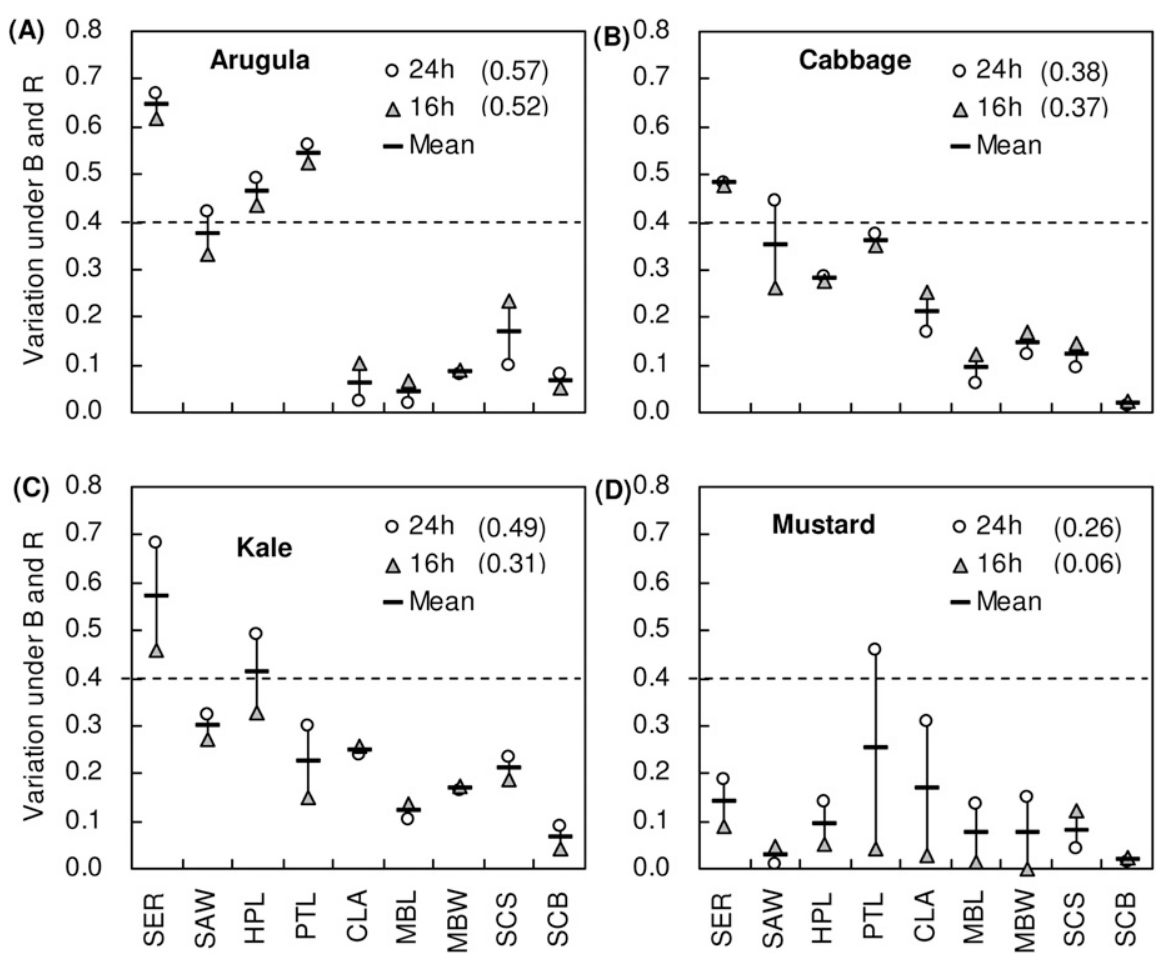

Fig. 4. Variation between blue (B) and red (R) light treatments under different photoperiods for the plant traits affected by light quality in four microgreen plant species; $24 \mathrm{~h}$ and $16 \mathrm{~h}$ indicate photoperiod of 24 and $16 \mathrm{~h}$. CLA = cotyledon area; $\mathrm{HPL}=$ hypocotyl length; $\mathrm{MBL}=$ maximum blade length; $\mathrm{MBW}=$ maximum blade width; $\mathrm{PTL}=$ petiole length; $\mathrm{SAW}=$ ratio of stem/aerial dry weight; $\mathrm{SCB}=$ stem color brightness; $\mathrm{SCS}=$ stem color saturation; $\mathrm{SER}=$ main stem extension rate. For each plant trait, variation under $\mathrm{B}$ and $\mathrm{R}$ was indicated by the $\mathrm{CV}$ (standard deviation/mean). The number in the brackets beside the legends is the mean variation of three elongation growth traits (SER, HPL, and PTL) under each photoperiod. The dash lines indicate a variation value of 0.4 .

effects between plant species and light quality on all the plant traits affected by light quality. Generally, mustard showed the lowest sensitivity in elongation response to $\mathrm{B}$ vs. $\mathrm{R}$ light under either 24-h or 16-h photoperiod among all the tested species (Fig. 4). It appeared that for red-leafed mustard, elongation promoted by blue light was less obvious, compared with other green-leafed species. A similar different elongation response to $\mathrm{B}$ vs. $\mathrm{R}$ light was achieved in the seedlings of different cabbage cultivars with different leaf color: 'Kinshun' (green leaf), and 'Red Rookie' (red leaf) (Mizuno et al., 2011). Possibly, the different leaf color can partly help explain the species' difference in elongation response. For redleafed mustard rather than other greenleafed species, the increased red pigments in the cotyledons might increase the reflection and then reduce the transmission of red light to its main photoreceptors, phytochromes. Previous studies have indicated that the blue light promoted elongation is related to weak phytochrome activity compared with red light (Kong et al., 2018) and stem elongation signal comes from phytochromes in cotyledons (Black and Shuttleworth, 1974; Kim et al., 2016). Under lower light levels (i.e., $100 \mu \mathrm{mol} \cdot \mathrm{m}^{-2} \cdot \mathrm{s}^{-1}$ ), the reduced red light signaling in red-leafed mustard rather than other green-leafed species might trigger similarly weak phytochrome activity as blue light.
In the present study, although there were species variations in responses to $B$ vs. $R$ light, the interaction between plant species and light quality appeared to be independent of photoperiod, which confirmed our third hypothesis that species differ in elongation response to blue light, and the difference is unaffected by photoperiod. For example, under either 24-h or 16-h lighting, arugula and mustard showed the highest and lowest sensitivity, respectively, in response to B vs. $\mathrm{R}$ light among the four species (Fig. 4). This was also supported by the result that there were no interaction effects of species $\times$ photoperiod $\times$ light quality, despite significant interaction effects of species $\times$ light quality on all the plant traits affected by $B$ vs. R light. Previous studies indicate that blue-light-mediated elongation response is a shade-avoidance response with varying sensitivity among species (Kong et al., 2018, 2019). Possibly, the species difference in elongation promoted by $\mathrm{B}$ vs. $\mathrm{R}$ light is due to inherent genetic differences in response to shade (Gommers et al., 2013), which may not be removed by change in some environmental factors, such as photoperiod.

In summary, at a PPFD of $\approx 100 \mu \mathrm{mol} \cdot \mathrm{m}^{-2} \cdot \mathrm{s}^{-1}$, monochromatic blue vs. red LED light can also promote elongation growth under 16-h lighting for the tested microgreen species except mustard. The promotion effects by blue light are more obvious under 24-h than 16-h lighting in most cases. However, species vary in elongation response to blue light regardless of photoperiod. It suggests that blue-light-promoted elongation growth is not an artifact specifically from 24-h lighting, implying a potential use of monochromatic blue LED light to promote hypocotyl elongation of some microgreen species.

\section{Literature Cited}

Bergstrand, K.-J.I. 2017. Methods for growth regulation of greenhouse produced ornamental pot-and bedding plants - a current review. Folia Hort. 29:63-74.

Black, M. and J.E. Shuttleworth. 1974. The role of the cotyledons in the photocontrol of hypocotyl extension in Cucumis sativus L. Planta 117:57-66.

de Wit, M., D.H. Keuskamp, F.J. Bongers, P. Hornitschek, C.M.M. Gommers, E. Reinen, C. Martinez-Ceron, C. Fankhauser, and R. Pierik. 2016. Integration of phytochrome and cryptochrome signals determines plant growth during competition for light. Curr. Biol. 26:3320-3326.

Fan, X., J. Zang, Z. Xu, S. Guo, X. Jiao, X. Liu, and Y. Gao. 2013. Effects of different light quality on growth, chlorophyll concentration and chlorophyll biosynthesis precursors of non-heading chinese cabbage (Brassica campestris L.). Acta Physiol. Plant. 35:2721-2726.

Fukuda, N., C. Ajima, T. Yukawa, and J.E. Olsen. 2016. Antagonistic action of blue and red light on shoot elongation in petunia depends on gibberellin, but the effects on flowering are not generally linked to gibberellin. Environ. Exp. Bot. 121:102-111.

Gommers, C.M.M., E.J.W. Visser, K.R. St Onge, L.A.C.J. Voesenek, and R. Pierik. 2013. Shade tolerance: When growing tall is not an option. Trends Plant Sci. 18:65-71.

Heo, J., C. Lee, D. Chakrabarty, and K. Paek. 2002. Growth responses of marigold and salvia bedding plants as affected by monochromic or mixture radiation provided by a light-emitting diode (LED). Plant Growth Regulat. 38:225230.

Hernández, R. and C. Kubota. 2016. Physiological responses of cucumber seedlings under different blue and red photon flux ratios using LEDs. Environ. Exp. Bot. 121:66-74.

Hirai, T., W. Amaki, and H. Watanabe. 2006. Action of blue or red monochromatic light on stem internodal growth depends on plant species. Acta Hort. 711:345-350.

Huché-Thélier, L., L. Crespel, J. Le Gourrierec, P. Morel, S. Sakr, and N. Leduc. 2016. Light signaling and plant responses to blue and UV radiations - perspectives for applications in horticulture. Environ. Exp. Bot. 121:22-38.

Jones-Baumgardt, C., D. Llewellyn, Q. Ying, and Y. Zheng. 2019. Intensity of sole-source lightemitting diodes affects growth, yield and quality of Brassicaceae microgreens. HortScience 54:1168-1174.

Keller, M.M., Y. Jaillais, U.V. Pedmale, J.E. Moreno, J. Chory, and C.L. Ballare. 2011. Cryptochrome 1 and phytochrome B control shade-avoidance responses in Arabidopsis via partially independent hormonal cascades. Plant J. 67:195-207.

Kim, E.Y., S.A. Park, B.J. Park, Y. Lee, and M.M. Oh. 2014. Growth and antioxidant phenolic compounds in cherry tomato seedlings grown under monochromatic light-emitting diodes. Hort. Environ. Biotechnol. 55:506-513.

Kim, J., K. Song, E. Park, K. Kim, G. Bae, and G. Choi. 2016. Epidermal phytochrome B inhibits 
hypocotyl negative gravitropism non-cell autonomously. Plant Cell 28:2770-2785.

Kong, Y., K. Schiestel, and Y. Zheng. 2019. Pure blue light effects on growth and morphology are slightly changed by adding low-level UVA or far-red light: A comparison with red light in four microgreen species. Environ. Exp. Bot. 157:58-68.

Kong, Y., M. Stasiak, M.A. Dixon, and Y. Zheng. 2018. Blue light associated with low phytochrome activity can promote elongation growth as shade-avoidance response: A comparison with red light in four bedding plant species. Environ. Exp. Bot. 155:345-359.

Kong, Y. and Y. Zheng. 2019. Variation of phenotypic responses to lighting using combination of red and blue light-emitting diodes versus darkness in seedlings of 18 vegetable genotypes. Can. J. Plant Sci. 99:159-172.

Kopsell, D.A. and C.E. Sams. 2013. Increases in shoot tissue pigments, glucosinolates, and mineral elements in sprouting broccoli after exposure to short-duration blue light from light emitting diodes. J. Amer. Soc. Hort. Sci. 138:31-37.

Kozai, T. 2018. Smart plant factory: The next generation indoor vertical farms. Springer, Singapore.
Kozai, T., G. Niu, and M. Takagaki. 2015. Plant Factory: An Indoor Vertical Farming System for Efficient Quality Food Production. Academic Press, Amsterdam.

Kyriacou, M.C., Y. Rouphael, F. Di Gioia, A. Kyratzis, F. Serio, M. Renna, S. De Pascale, and P. Santamaria. 2016. Micro-scale vegetable production and the rise of microgreens. Trends Food Sci. Technol. 57:103-115.

Li, H., C. Tang, Z. Xu, X. Liu, and X. Han. 2012. Effects of different light sources on the growth of non-heading chinese cabbage (Brassica campestris L.). J. Agr. Sci. 4:262-273.

Mizuno, T., W. Amaki, and H. Watanabe. 2011. Effects of monochromatic light irradiation by LED on the growth and anthocyanin contents in leaves of cabbage seedlings. Acta Hort. 907:179-184.

Pedmale, U.V., S.C. Huang, M. Zander, B.J. Cole, J. Hetzel, K. Ljung, P.A.B. Reis, P. Sridevi, K. Nito, and J.R. Nery. 2016. Cryptochromes interact directly with PIFs to control plant growth in limiting blue light. Cell 164:233245 .

Sager, J.C., W.O. Smith, J.L. Edwards, and K.L. Cyr. 1988. Photosynthetic efficiency and phy- tochrome photoequilibria determination using spectral data. Trans. ASAE 31:1882-1889.

Schüssler, H.K. and K.J. Bergstrand. 2012. Control of the shoot elongation in bedding plants using extreme short day treatments. Acta Hort. 956:409-415.

Schwend, T., D. Prucker, and H. Mempel. 2015. Red light promotes compact growth of sunflowers. Eur. J. Hort. Sci. 80:56-61.

Stutte, G.W. 2009. Light-emitting diodes for manipulating the phytochrome apparatus. HortScience 44:231-234.

Sysoeva, M.I., E.F. Markovskaya, and T.G. Shibaeva. 2010. Plants under continuous light. Plant Stress 4:5-17.

Warrington, I.J. and R.A. Norton. 1991. An evaluation of plant growth and development under various daily quantum integrals. J. Amer. Soc. Hort. Sci. 116:544-551.

Wu, M., C. Hou, C. Jiang, Y. Wang, C. Wang, H. Chen, and H. Chang. 2007. A novel approach of LED light radiation improves the antioxidant activity of pea seedlings. Food Chem. 101:1753-1758.

Yamaguchi, S. 2008. Gibberellin metabolism and its regulation. Annu. Rev. Plant Biol. 59:225251. 